\title{
The burgeoning interest in young onset dementia: redressing the balance or reinforcing ageism?
}

\author{
By EDWARD TOLHURST*
}

\begin{abstract}
Critical evaluation is undertaken of social scientific conceptualisations of dementia in relation to ageing. In response to the societal tendency to associate dementia with old age, there is a growing body of literature that seeks to explicate the particular challenges faced by younger people with the condition. While recognition of the distinctive impacts presented by dementia at different ages is crucial, an age-related conceptual model that focuses on a lifecourse divide at age 65 is problematic: it promulgates a sense that younger people with dementia have "unique" experiences, while dementia for older people is typical. This also reflects a societal ageism, under which concerns are focused on those situated within "productive adulthood." Moreover, a straightforward chronological marker cannot adequately represent a social world shaped by significant demographic changes. A more textured appreciation of ageing and dementia is required to help articulate how distinctive experiences emerge across the lifecourse.
\end{abstract}

Keywords: ageing, dementia, third age, social location, young onset dementia.

* Edward Tolhurst, Faculty of Health Sciences, Staffordshire University, UK 
International Journal of Ageing and Later Life

\section{Introduction}

Dementia is defined as "young onset" when it occurs before the age of 65 . While dementia disproportionately affects older people, a significant number of younger people have the condition under the age of 65 . For example, it is estimated that 850,000 people have dementia in the UK and, of these, approximately 42,000 have young onset dementia (Alzheimer's Society 2014). The development of research into young onset dementia has occurred as the needs of these younger people with the condition have been insufficiently recognised. Dementia is traditionally perceived to be a disease of old age (Harris 2004), and research has tended to sample all age groups together, with the result that the particular needs of younger people have been difficult to discern (Clemerson et al. 2014). The manner in which social scientific research has addressed younger people with dementia requires closer consideration to assess the extent to which it positively redresses this imbalance. Additionally, scrutiny is required as to whether any unintended consequences are generated by this approach, which could have negative implications for people with dementia and their family members.

The importance of conceptualising ageing in relation to dementia relates to the concept of "personhood." Dementia has principally been understood as a terminal biomedical condition defined by neurodegeneration. Such a perspective prompts a tendency to perceive the experience of the condition in homogenised terms, with the deleterious effects of the condition seen to determine experience. The person with dementia's experiential domain, however, is a complex phenomenon: it is not only affected by neurological factors, but by relationships and social contexts. "Personhood should be viewed as essentially social: it refers to the human being in relation to others" (Kitwood \& Bredin 1992: 275).

Recognition of the complexity of social and relational influences contributes to an awareness of the uniqueness of persons (Kitwood 1997). Age is one such attribute that contributes to this uniqueness. An appropriate representation of personhood thus requires recognition of heterogeneity of experience, and this includes recognising how lifecourse positioning shapes the socially situated basis of experience. Acknowledging the influence of characteristics, such as age, can thereby help to prevent the illness trajectory from being viewed as the central orientating aspect of experience (Bartlett \& O'Connor 2010). An effective age-related model of 
dementia research is therefore required to advance a positive and enabling conceptualisation of personhood.

This article presents an overview of the present social scientific context of young onset dementia and how this has developed. This overview provides a platform for the evaluation of several strands of the current social scientific model of ageing in relation to dementia. Insights are accordingly offered into how this conceptual model might assist or impede understandings of the experience of living with dementia. ${ }^{1}$

\section{The Academic Context of Dementia and Ageing}

\section{Young Onset Dementia: Redressing the Balance}

The requirement to address the needs of younger people with dementia has received increasing academic attention over the last two decades. Keady and Nolan (1994) highlighted that there was a particular absence within research of the perspective of younger people with dementia. Since this time there has been a steadily growing body of literature on young onset dementia, with output on the topic increasing in the last decade. The atypical nature of young onset dementia, in terms of the age of onset of the condition, has prompted researchers to explore its distinctive experiential dimensions. For example, Killick (1999) states that special emphasis needs to be placed upon communicating with the younger age group of people with dementia. Furthermore, they are "often much closer in age to the central concerns of their lives than older people" (Killick 1999: 171); these include family events, relationships and working roles.

Harris (2004) highlights the distinctive needs of younger people with the condition: "Though there are some similar experiences with people of all ages who have dementia, the strength and depth of the impact is greater

\footnotetext{
${ }^{1}$ The nomenclature relating to younger people with dementia is debated within academic literature, with it referred to inter alia as "early onset dementia" or "young onset dementia." The latter of these terms is used principally in this article. It has been highlighted that "early onset" runs the risk of being conflated with "early-stage" dementia, that is, the initial stages of dementia rather than the age at which the condition is diagnosed (Koopmans \& Rosness 2014).
} 
International Journal of Ageing and Later Life

for younger people and their families" (Harris 2004: 33). This is underscored by Harris and Keady (2009) who highlight that "for the younger individuals with dementia and their family members, the disease occurs 'off time', not in their older years, as most often expected, but in the prime of their lives" (Harris \& Keady 2009: 442). In addition, Svanberg et al. (2011) argue that people with young onset dementia might have additional needs as a consequence of the "non-normative" timing of the condition. Challenges of young onset dementia thus relate to the position in the lifecycle at which dementia is diagnosed: developing the condition in middle age limits people's ability to fulfil age-related goals linked to the sharing of skills and expertise with wider society, "thereby disrupting lifecycle hopes and expectations" (Clemerson et al. 2014: 462). The distinctive positioning of young onset dementia is reinforced by Chaston (2011) who states that younger people are more likely to be sexually active, and are also prone to encountering particular challenges associated with having dependent children.

The perspective that younger people with dementia and their families have different needs and require additional support/specific services has been reinforced in a number of papers (e.g. Armstrong 2003; Beattie et al. 2004; Johannessen \& Möller 2013; Lockeridge \& Simpson 2013; Roach et al. 2008, 2016).

It is also important to acknowledge how the overall configuration of services shapes conceptualisations of age-related aspects of dementia. The historical development of healthcare in the UK has separated mental health services into general psychiatry and old-age psychiatry, with the demarcation between these services being age 65 . The traditional separation of general psychiatry and old-age psychiatry is still likely to impact upon the experience of services, with many younger people falling through the net of health and social services (Royal College of Psychiatrists and Alzheimer's Society London 2006). This perspective is endorsed by Werner et al. (2009) who state that the lack of special services for younger people with dementia might "be attributed to the fact that professional staff in general psychiatric services frequently lack adequate knowledge and training to recognize and treat such disorders. At the same time, elder care services ... are inappropriate for younger persons with dementia" (Werner et al. 2009: 634). 


\section{Recognition of the Threat of Ageism}

While the principal orientation towards young onset dementia has been a promotion of the specific needs of this age group, recognition that this focus might generate some unwanted corollaries has been recorded. For example, it has been acknowledged that there might be an ageism inherent in approaches that set out to establish distinctive age-based requirements of older people: "At best these arguments relate to different positions in the lifecourse, at worst they may be seen as inherently ageist in their implicit acceptance of older people's reduced social roles, anticipated poor health and disability" (Tindall \& Manthorpe 1997: 244). It has also been noted that 65 is an arbitrary divide that perpetuates ageist assumptions, but that the focus on younger people with dementia is required to redress an inequitable balance in service provision (Cox \& Keady 1999).

In addition, Reed et al. (2002) reported on an evaluation of a project that was developed to offer "age-sensitive" care to younger people, and used a range of data sources including qualitative interviews with people with dementia, carers and project staff. People with dementia did not discuss particular age-related issues, "but talked about the distress and confusion that could be expected of anyone who has been given a diagnosis of dementia for themselves or a family member" (Reed et al. 2002: 110). The responses of those using the service were very positive, but this reflected the fact that a well-resourced team was able to offer extensive support rather than address any age-specific needs.

A further key advantage of specialist services for younger people is that they are differentiated from those for older people: services for older people are generally viewed as low-status (Reed et al. 2002). Greater social and political interest is likely to be generated in dementia by highlighting that it affects younger people and is not, therefore, just a disease of old age: this aligns the debate with broader age-related values of society, which prioritise youth ahead of old age (Segal 2013). A key advantage to the construction of a definable cohort of younger people with dementia is that it distinguishes them from societally undervalued and stigmatised older people.

Despite these recognitions, cautionary notes with regard to a focus on young onset dementia have become submerged under a persistent unitary discourse that sets out to promote the distinctive requirements of younger people with dementia. Alternative perspectives which might engage 
International Journal of Ageing and Later Life

critically with, and enhance, this discourse have not been developed, with a mode of groupthink on dementia and ageing seemingly taking hold.

\section{Older People: The Absence of Age-Related Experiential Factors}

It is vital to recognise that dementia does not just affect older people and literature that focuses on younger people assists with the promotion of this recognition. This offers some counterbalance to dementia research that has tended to overlook the impacts of the condition on younger people. In addition, the focus on young onset dementia highlights that life-cycle positioning will shape the experience of the condition, and that services should be attuned to these age-related influences. Nevertheless, a new imbalance has been generated by the focus on young onset dementia, as it means that age-sensitive approaches to dementia are almost exclusively oriented towards younger people. As highlighted above, young onset dementia literature, while only a subset of the field as a whole, does actively scrutinise age-based dimensions of experience. Alternatively, while most dementia research may address older people this tends to be presented in age-neutral terms.

Examples of research studies which directly state that they address the perspectives of older people are Steeman et al. (2007); Cowdell (2010); and Dalby et al. (2012), but specific age-related features of experience are generally overlooked in these papers. Even studies which explicitly address older people and identity do not interrogate research participants' particular age-related requirements or attributes (Caddell \& Clare 2013; Cohen-Mansfield et al. 2000). Furthermore, Hulko (2009) adopts an approach which is sensitive to how social location shapes the experience of dementia for older people. Evaluation of social location requires sensitivity to how the person's experiential context is shaped by characteristics such as gender, ethnicity and class. However, despite adopting a direct focus on social location, age is the particular characteristic that does not receive close scrutiny. When the specific impacts of age are referred to directly within dementia literature these do not tend to be explored extensively and focus on factors such as negative societal perceptions of old age (Hubbard et al. 2003), or the increasing losses associated with old age (Preston et al. 2007).

Within the corpus of dementia literature, the exploration of specific agerelated factors beyond a focus on young onset dementia is therefore marginal. 
The discourse associating dementia with old age means that the distinctive aspects of age-specific experience are apparently considered to have less significance for older people. This renders the experience of dementia for older people age-typical. Accordingly, literature which addresses older people utilises this designation as a descriptive sample characteristic rather than as an analytic driver, with "older people with dementia" and "people with dementia" essentially synonymous.

\section{Evaluation of the Binary Model of Dementia and Ageing}

As discussed above with reference to personhood, it has been perceived that a shortcoming within dementia literature has been the conceptualisation of the condition in homogenous terms. The focus on young onset dementia addresses this to some extent via its proposal that the condition is experienced differently by younger people. This prevents an entirely uniform perspective on dementia with reference to age from being promoted. Nevertheless, the alternative model proffered, which divides people with dementia into two groups at the age of 65 , presents its own potential impediments to understanding the experience of dementia: a homogenous age-neutral model has been replaced by a binary model. The focus on a divide at age 65 prompts a sense of two age groups and thus promotes a dichotomous perspective of dementia experience. The following sections address some of the potential, and unwanted, outcomes of this binary model.

\section{Underplaying the Challenges of Dementia for Older People}

Several authors refer to the "unique" challenges of young onset dementia (Chaston 2011; Clemerson et al. 2014; Harris 2004; Harris \& Keady 2009). The use of this absolute term pushes the sense of difference between age groups to an extreme, and beyond the reasonable assertion that younger people are more likely to encounter particular challenges. Ascribing unique experiences or challenges to a large and varied group of people (which is narrowly demarcated from another large and varied group of people) is surely to misdescribe a complex reality. It suggests that people under the age of 65 have experiences that are incontrovertibly distinct from all people aged 65 and over. This is not just a matter of semantic and conceptual 
International Journal of Ageing and Later Life

quibbling: the use of the term "unique" indicates the manner in which agerelated discourses associated with dementia research have become skewed excessively towards younger people. A commensurate focus on the unique age-related challenges of older onset dementia is much less apparent within the literature.

The binary model is thus underpinned by two broad categories: firstly, younger people (aged under 65) whose experience is shaped by specific age-related factors; and secondly, older people (aged 65 and over) who provide an inert control group against which the greater challenges of younger people can be contrasted. The use of other terminology such as "off-time" and "non-normative" in relation to young onset dementia also implies that the dementia for older people is "on-time" or "normative." In fact, Harris (2004) endorses this perspective, highlighting that dependencies encountered in old age are experienced as "on-time." This use of terminology actually embeds a sense that dementia is a feature of normal ageing, when it is well documented that this is not the case (e.g. Graham \& Warner 2009; Hughes 2014). Even in terms of prevalence, people aged 95 and over with dementia are outnumbered by those who do not have the condition: $41.1 \%$ in this age range are estimated to have dementia (Alzheimer's Society 2014).

The association of dementia with a sense of normalcy, typicality or expected timing for older people is not just misleading, but could also lead to the experiential impacts of the condition for older people being underplayed. The fact that dementia is a terminal condition will present substantial emotional challenges to people with the condition and their family members. Moreover, the neurodegenerative impacts of the illness, which often affect memory, behaviour and communication, are also likely to present very intense difficulties. These challenges are likely to be encountered as disconcerting and painful regardless of the age at which dementia is diagnosed. Highlighting the distinctive challenges faced by younger people does not, of course, intrinsically diminish recognition of more generalisable challenges of dementia (Tolhurst et al. 2014). However, a persistent imbalanced focus on the particular age-related dimensions of young onset dementia (and its associated terminology) does generate a sense that an expectation of decline in old age will render the experiential impacts of dementia easier to manage. 
A zero-sum situation is thus constructed whereby the promotion of the "unique" needs of one age group (younger people) leads to a diminution in recognition of the needs of another group (older people). The personhood debate sets out to illuminate the uniqueness of persons by highlighting the breadth of relational and social factors that shape experience. A partial focus on the particular challenges faced by people with young onset dementia has the scope to diminish our apprehension of the distinctive experiences encountered by people aged 65 and over. While a uniformly negative representation of the condition should certainly not be promulgated, dementia does present intense and multiple difficulties to those living with the condition.

While dementia has been conceptualised in homogenous terms, it is also important to note that older people have also been socially defined as a homogenous group. For example, there is a tendency to equate old age with illness states and such a conceptualisation contributes to later life being bracketed off as a homogenous category (Higgs \& Rees-Jones 2009). Developing a model of research under which dependency in old age is considered to be an "on-time" occurrence is commensurate with this homogenising tendency. The endeavour to overcome monolithic representations of dementia via a focus on younger people has generated the unfortunate outcome of reinforcing monolithic representations of older people. It is not just the case that a focus on young onset dementia is at risk of underplaying the significance of the condition for older people, but that this orientation could also compound negative, homogenising representations of old age. Therefore, a model that underplays the intensity and breadth of experiential challenges presented by dementia to older people should be resisted.

\section{Reinforcing a Societal Focus on "Productive Adulthood"}

Particular social and cultural values also impact upon age-related statuses and experiences. For example, the traditional means by which labourmarket participation and retirement have been constructed shape definitions of old age and, as a corollary, influence health service configurations and models of age-related research. The process of defining people as old at the age of 65 became institutionalised through state policies related to labour-market participation, retirement and pension entitlements 
International Journal of Ageing and Later Life

(Higgs \& Gilleard 2014). This was the age at which it was expected working life would come to a conclusion, followed by a shorter period of retirement. State policies were accordingly devised upon this assumption and this, in turn, reinforced definitions of old age based upon the age of 65 . While the state pension age is set to rise in the UK, and the default retirement age was rescinded in 2011, the influence of these aforementioned definitions endures.

The productive endeavours of those engaged in paid employment are highly valued in society as they offer the means by which economic contributions are generated via taxation. The individual accumulation of wealth through personal endeavour accordingly takes on a moral virtue: heightened expectations of rationalism and economic productivity therefore "inevitably influence our sense of worth of a human life" (Post 2000: 5). These values are particularly favoured within neo-liberal societies which promote the sovereignty of the self-sufficient, autonomous individual. A socio-economic context of neo-liberalism has shaped social conditions in the UK since the early 1980s and this represents a broad shift from collectivist models of social welfare to a more individualistic model of selfreliance (Bauman 2011). The uncritical retention of age 65 within dementia research as a key marker thus reflects a societal and cultural promotion of "productive adulthood" as the sovereign lifecourse stage.

Such rhetoric can render the experience of ageing morally challenging. The prevailing climate of benefit retrenchment and targeting those perceived to be undeserving welfare recipients means that older people with genuine need still feel the threat of stigma related to dependency. Older people are situated in a troublesome position as a consequence of discourses that associate paid work with productivity, and accessing support as contributing to economic hardship. The additional support needs prompted by dementia can also exacerbate feelings of dependence. Those who do require external support might therefore feel a sense of guilt that they are unable to measure up to societal values of independence and selfsufficiency, and could accordingly feel a social burden. "Dependency is a sign of not being healthy, of being passive, of not being self-reliant and not being a 'proper' person in society" (Weicht 2011: 214).

The fact that young onset dementia is sometimes referred to as "working age dementia" (Alzheimer's Society 2015), with some NHS 
services employing this term, reinforces the perspective that discourses on ageing, dementia and adult productivity are aligned. The utilisation of the "working age" term underscores the association between conceptualisations of ageing and employment status. Dementia for those under 65 therefore prompts particular public and academic interest as a consequence of the collision between an "off-time" illness and cultural expectations of adult productivity.

Sabat (2001) proposes that people have a range of attributes and social personae that should be recognised to prevent people from being positioned in limited and negative ways that undermine their personhood. This "malignant positioning" occurs if the focus of those seeking to support people with dementia becomes the perceived neurological effects of the condition, rather than the multiple factors that shape a person's subjective and relational being. The problem with an age-related model of dementia shaped by the centrality of "working age" is that it focuses excessively on social personae related to employment. This might accordingly marginalise the apprehension of a person's social and relational being that is unconnected with wage-based productivity. Lifecourse expectations are defined with reference to an idealised notion of productive adulthood; but by contrast, "children, young people, elders and disabled people of all ages have been constructed as lacking the kind of attributes upon which full personhood and citizenship are premised" (Priestley 2004: 97).

The aim should be to promote the personhood of all people with dementia, but a model with "productive adulthood" at its core could actually contribute to a malignant positioning of older people (and also younger people with dementia who are no longer able to work). Employment might of course have key intersections with the experience of dementia, and work is very often a key element of people's lives; but utilising it as the defining aspect of a model of age-related dementia research (or for the designation of specialist services) elevates its experiential significance too greatly.

\section{Conceptual Misalignment: Tertium Non Datur}

A conceptual challenge with a binary model, which relates to the arguments detailed above, is that it promulgates a sense of opposing states defined by difference. Young onset dementia literature is defined by the aim to differentiate the experience of younger people from that of older people. It is 
International Journal of Ageing and Later Life

therefore less accommodating of the similarities and experiential overlaps between the two groups.

A further shortcoming of a binary approach that promotes a focus on difference is that it rhetorically skews the two categories towards the extremities of the continuum. To appropriate a term from logic, the binary model thus generates an "excluded middle" - tertium non datur. The conceptual framework is built upon two oppositional states defined by difference; the third group which converges in the middle of these two groups is overlooked. Likewise it should be recognised that the two groups generated by the current age-related model of dementia research are very broad, that is, under 65 , and 65 and over. An essentialist binary age-based model ascribes an illegitimate experiential unity to these two groups, and also prompts a misleading sense of dichotomy between these same groups. Consequently, it does little to promote the heterogeneity of the experience of living with dementia.

By promoting a sense of binary opposition, this model overlooks the ages at which the model converges, that is, the age of 65 . The rhetoric of young onset dementia, as discussed above, is potentially misleading in that it is most readily associated with people in the centre of their working careers, and with dependent children. However, the prevalence of dementia increases with age: the period between the ages of 60 and 65 is the time when people who meet the "young onset" definition are most likely to be diagnosed with dementia. While generalisations should be avoided, this is the age range where people are increasingly likely to have grandchildren and be considering retirement. The binary model is therefore at risk of failing to represent the experience of the majority of people with young onset dementia: its predication on oppositional states means that it is oriented towards the youngest people with the condition. In addition, dementia for those over 65 is defined by what could be termed "extreme old age" and its associations with comorbidity, dependence and decline.

The people most likely to be misrepresented under a binary model of ageing and dementia are those just over the age of 65 . People diagnosed at this time are not represented by the "young onset dementia" definition, but neither is 65 considered to be a meaningful indicator of the commencement of old age in contemporary society. This is explored below with reference to the "third age" concept. 


\section{Failing to Account for Demographic Change: The "Third Age"}

In the UK the average life expectancy at birth for men is 79.1 years and for women it is 82.8 years. In 1980, it was 70.8 and 76.8 years respectively (ONS 2015). On its own this substantial increase in life expectancy suggests that a fixed conceptual distinction is unlikely to offer enduring utility when offering insights into the nature of age and ageing. This demographic trend means that: "We are at the end of the old 'old age'... If we ignore the implications of the longevity revolution and fail to plan for the radically different world that will soon surround us, crisis will be upon us" (Kirkwood 2001: 17). As a consequence of the promotion of the age of 65 as a fixed demarcation between young and old, the present conceptual model of dementia and ageing is ill-equipped to account for this longevity revolution.

It is not simply the case that life expectancy is increasing, but also that longevity and demographic changes are altering the experience of ageing. Longevity means that later life is becoming more complex, and is shaped by a "third age" that describes the increasingly lengthy period of the lifecourse following paid employment and before physical decline. "The third age has been established on the basis of a materially secure retirement, realized through the participation of an increasing number of social actors occupying diverse identities and statuses, across widening social spaces" (Gilleard \& Higgs 2005: 17). The period following retirement is viewed as a time offering possibilities and freedom: people within the parameters of the third age can, within broad limits, live their lives as they please, before encountering a "fourth age" of decline (Weiss \& Bass 2002).

As a consequence the third age has been referred to as "the crown of life" where the individual occupies a lifecourse position that is distanced from both the obligations of younger adulthood and the infirmities of old age (Gilleard \& Higgs 2010). This is a consequence of the ageing population but also rises in living standards which have changed expectations for retirement (Higgs 2013). The "third age" concept demonstrates that it is vital to recognise how the changing nature of the lifecourse intersects with the experience of dementia. This could be overlooked if the age-related focus remains fixed on dementia for those under 65, with people over this age remaining conceptualised as a homogenous group. It is argued that a simple chronological marker is no longer sufficient and this argument is 
International Journal of Ageing and Later Life

centred on "the changing nature of what old age has become and how it has been successively changed from being simply retirement from the labour force to becoming a distinct part of a more culturally and diverse later life" (Higgs 2013: 213).

The notion that young onset dementia occurs off-time and accordingly dependency in older age is a "normative" phenomenon (and is therefore likely to be felt less acutely) does not account for the changing nature of ageing in societies. Retirement, for example, will offer an increasing sense of extensive possibilities and potential for many people. The tone of current literature on young onset dementia could prompt a belief that ageing and breadth of experience have a straightforward inverse relationship. However, retirement itself might offer opportunities to engage in volunteering opportunities, take on extra responsibilities with grandchildren or other younger family members, or pursue travel plans. Dementia is likely to present substantial challenges at any age, but emotional difficulties might be felt particularly acutely if it coincides with a period of the lifecourse where new possibilities and time-freedom were anticipated. Disruption of life-cycle hopes and expectations is not, therefore, exclusive to those aged under 65.

Discourses on the third age, and associated concepts such as successful ageing, also present a framework of social expectations by which people judge the quality of their own lives. Failing to measure up to these expectations could present challenges to older people, as positive views of ageing are explicitly or implicitly set against unsuccessful or negative ageing (Higgs \& Gilleard 2015). The argument is not, therefore, that the third age/ fourth age distinction offers a sufficient alternative model to explicate the experience of dementia and ageing, as this approach raises potential challenges of its own. What is being argued is that these insights from the sociology of ageing underscore that the lifecourse is a more complex phenomenon than that represented by the binary framework of ageing currently defining dementia research.

Perspectives on the third age demonstrate that the current age-related dementia model is unlikely to represent the experience of a very substantial proportion of people over the age of 65 . The number of people experiencing a period of affluent and healthy ageing is expanding, with a fourth age of decline an ancillary social category. Nevertheless, the current age-related 
model of dementia research does not map cogently on to these social conditions. With its uneven focus on the distinctive challenges faced by younger people, this model fails to account for the changing nature of old age: the burgeoning third age is actually overlooked as a consequence of the "excluded middle" which inheres within its young/old dichotomy. Instead, the suggestion that challenges and dependency are experienced as "on-time" for people over the age of 65 means that they are aprioristically aligned with the "fourth age" category.

\section{Conclusion}

The lifecourse is a complex phenomenon which intersects with a range of subjective, interactional and social factors. This article has demonstrated that it cannot be properly understood with reference to a dichotomous model: an age-sensitive approach to dementia research must be founded on a more sophisticated basis than a socially constructed divide at age 65 . As has been noted above, the current focus of age-based scrutiny is on one side of this dichotomy, that is, young onset dementia. The present model thus sets inflexible and skewed parameters for research; however, reframed conceptualisations of ageing and dementia can encourage researchers to reorient their empirical approach. The boundaries of samples in age-related research, for example, do not need to be devised solely with reference to the age of 65 . A variegated approach to sample composition would contribute to a mode of enquiry that is more receptive to the complex intersections between dementia, ageing and the experience of living with the condition. The current model also prompts an approach to analysis concerned with experiential divergences between younger and older people with dementia. A more credible analytical method would be attuned to the identification of divergences and commonalities of experience that feature across various life stages.

In defence of the current model, its well-meaning message has arguably required persistent iteration, as the oft-stated need for more age-specific provision for younger people remains unheeded (Roach et al. 2012). However, the understandable eagerness to promote the particular needs of younger people has unfortunately elevated the age of 65 from an arbitrary dividing line to a sovereign (and spurious) experiential boundary. 
International Journal of Ageing and Later Life

Approaches to the theorising and research of dementia certainly need to be cognisant of the format of services, as the recommendations of practically oriented studies must relate to what can be feasibly implemented. However, there is no requirement that the call for greater young onset services should define the entire age-related dementia model. In fact, one of the curiosities of the young onset dementia debate is its determination to replicate the age-based parameters of psychiatric services (which are themselves framed by outdated societal definitions of old age related to economic productivity).

This article in no way sets out to challenge the principle of age-specific services. Health services or support organisations might opt to select an age-divide for the delivery of provision, even if it is recognised that this can only be an approximate indication of different needs within the population. A conceptual model built upon these professionally constructed foundations, however, does not inhabit the optimal vantage point from which the utility (and implications) of such service configurations can be evaluated. The way that we research and think about dementia, in relation to age, does not need to be determined by a professional division of services. Societal norms and the configuration of services are factors that will, of course, shape the experience of dementia. But the aim should be to explore and illuminate how social structures and cultural values shape experience, rather than unreflexively endorsing these phenomena and further entrenching their impact.

Crucially, the current age-related model focused on younger people with dementia is incommensurable with the broader intentions of experientially oriented research. This article has demonstrated that this is not just a conceptual debate: models of ageing have the scope to reinforce ageism and impact negatively upon the experience of dementia. Repeated statements on the particular needs of younger people run the risk of compounding homogenising and exclusionary discourses on older people. Assumptions of on-time dependency and older people existing beyond the prime of their lives could actually contribute to a malignant positioning that undermines the personhood of those with dementia aged 65 and over.

A new conceptual approach can address the way in which emergent experiential factors related to age shape experience across the lifecourse. This will also accommodate the requirement to promote the needs of 
specific age groups, without compounding negative societal representations of old age. This more nuanced model would not promote an ontologically flat model of ageing, which denies that particular experiences are more likely to arise at different ages. What is being promoted is an approach that recognises age as complex experiential continuum, which is not readily compartmentalised into two stages divided by a static chronological marker.

\section{Acknowledgements}

An earlier version of this article was presented at the 2nd midterm conference of the Research Network on Ageing in Europe, European Sociological Association. This was held from 18th to 20th September 2014 in Klagenfurt, Austria. I would like to thank Prof Paul Kingston at The University of Chester for his guidance during the research that inspired this article. I am also grateful for comments on previous drafts provided by Mark Lovatt at Staffordshire University.

\section{Corresponding Author}

Edward Tolhurst, Faculty of Health Sciences, Staffordshire University, Blackheath Lane, Stafford, ST18 0AD, United Kingdom. Email: e.tolhurst@ staffs.ac.uk

\section{References}

Alzheimer's Society. (2014). Dementia UK: Update. London: Alzheimer's Society.

Alzheimer's Society. (2015). What is Young-Onset Dementia? Available on https://www.alzheimers.org.uk/site/scripts/documents_info.php? documentID=164 (Accessed: April 10, 2016).

Armstrong, M. (2003). The needs of people with young-onset dementia and their carers. Professional Nurse 18(12): 681-684.

Bartlett, R. \& O'Connor, D. (2010). Broadening the Dementia Debate: Towards Social Citizenship. Bristol: The Policy Press.

Bauman, Z. (2011). Collateral Damage: Social Inequalities in a Global Age. Cambridge, MA: Polity Press. 
International Journal of Ageing and Later Life

Beattie, A., Daker-White, G., Gilliard, J. \& Means, R. (2004). How can they tell?" A qualitative study of the views of younger people about their dementia and dementia care services. Health and Social Care in the Community 12(4): 359-368.

Caddell, L. \& Clare, L. (2013). A profile of identity in early-stage dementia and a comparison with healthy older people. Aging and Mental Health 17(3): 319-327.

Chaston, D. (2011). Between a rock and a hard place: Exploring the service needs of younger people with dementia. Contemporary Nurse 39(2): 130-139.

Clemerson, G., Walsh, S. \& Isaac, C. (2014). Towards living well with young onset dementia: An exploration of coping from the perspective of those diagnosed. Dementia 13(4): 451-466.

Cohen-Mansfield, J., Golander, H. \& Arnheim, G. (2000). Self-identity in older persons suffering from dementia: Preliminary results. Social Science and Medicine 51(3): 381-394.

Cowdell, F. (2010). Care of older people with dementia in an acute hospital setting. Nursing Standard 24(23): 42-48.

Cox, S. \& Keady, J. (1999). Introduction. In S. Cox \& J. Keady (eds.), Younger People with Dementia: Practice, Planning and Development (pp. 11-14). London: Jessica Kingsley.

Dalby, P., Sperlinger, D. \& Boddington, S. (2012). The lived experience of spirituality and dementia in older people living with mild to moderate dementia. Dementia 11(1): 75-94.

Gilleard, C. \& Higgs, P. (2005). Contexts of Ageing: Class, Cohort and Community. Cambridge, MA: Polity Press.

Gilleard, C. \& Higgs, P. (2010). Aging without agency: Theorizing the fourth age. Aging and Mental Health 14(2): 121-128.

Graham, N. \& Warner, J. (2009). Understanding Alzheimer's Disease and Other Dementias. Poole: Family Doctor Publications.

Harris, P. B. (2004). The perspective of younger people with dementia: Still an overlooked population. Social Work in Mental Health 2(4): 17-36.

Harris, P. B. \& Keady, J. (2009). Selfhood in younger onset dementia: Transitions and testimonies. Aging and Mental Health 13(3): 437-444. 
Higgs, P. (2013). Disturbances in the field: The challenge of changes in ageing and later life for social theory and health. Social Theory and Health 11(3): 271-284.

Higgs, P. \& Gilleard, C. (2014). Frailty, abjection and the "othering" of the fourth age. Health Sociology Review 23(1): 10-19.

Higgs, P. \& Gilleard, C. (2015). Rethinking Old Age: Theorising the Fourth Age. London: Palgrave.

Higgs, P. \& Rees-Jones, I. (2009). Medical Sociology and Old Age. London: Routledge.

Hubbard, G., Downs, M. \& Tester, S. (2003). Including older people with dementia in research: Challenges and strategies. Aging and Mental Health 7(5): 351-362.

Hughes, J. (2014). How We Think About Dementia: Personhood, Rights, Ethics, the Arts and What They Mean for Care. London: Jessica Kingsley.

Hulko, W. (2009). From "not a big deal" to "hellish": Experiences of older people with dementia. Journal of Aging Studies 23(3): 131-144.

Johannessen, A. \& Möller, A. (2013). Experiences of persons with earlyonset dementia in everyday life: A qualitative study. Dementia 12(4): 410-424.

Keady, J. \& Nolan, M. (1994). Younger onset dementia: Developing a longitudinal model as the basis for a research agenda and as a guide to interventions with sufferers and carers. Journal of Advanced Nursing 19(4): 659-669.

Killick, J. (1999). Dark head amongst the grey": Experiencing the worlds of younger persons with dementia. In S. Cox \& J. Keady (eds.), Younger People with Dementia: Planning, Practice and Development (pp. 153-172). London: Jessica Kingsley.

Kirkwood, T. (2001). The End of Age: Why Everything about Ageing is Changing. London: Profile Books.

Kitwood, T. (1997). Dementia Reconsidered: The Person Comes First. Buckingham: Open University Press.

Kitwood, T. \& Bredin, K. (1992). Towards a theory of dementia care: Personhood and well-being. Ageing and Society 12(3): 269-287. 
International Journal of Ageing and Later Life

Koopmans, R. \& Rosness, T. (2014). Young onset dementia - What does the name imply? International Psychogeriatrics 26(12): 1931-1933.

Lockeridge, S. \& Simpson, J. (2013). The experience of caring for a partner with young onset dementia: How younger carers cope. Dementia 12(5): 635-651.

ONS (Office for National Statistics). (2015). National Life Tables, United Kingdom, 2012-2014. London: The Stationery Office.

Post, S. (2000). The Moral Challenge of Alzheimer Disease: Ethical Issues from Diagnosis to Dying. Baltimore, MD: The John Hopkins University Press.

Preston, L., Marshall, A. \& Bucks, R. (2007). Investigating the ways that older people cope with dementia: A qualitative study. Aging and Mental Health 11(2): 131-143.

Priestley, M. (2004). Generating debates: Why we need a lifecourse approach to disability issues. In J. Swain, S. French, C. Barnes \& C. Thomas (eds.), Disabling Barriers, Enabling Environments (pp. 94-99). London: Sage.

Reed, J., Cantley, C., Clarke, C. L. \& Stanley, D. (2002). Services for younger people with dementia: Problems with differentiating needs on the basis of age. Dementia 1(1): 95-112.

Roach, P., Drummond, N. \& Keady, J. (2016). "Nobody would say that it is Alzheimer's or dementia at this age": Family adjustment following a diagnosis of early-onset dementia. Journal of Aging Studies 36: 26-32.

Roach, P., Keady, J. \& Bee, P. (2012). "It's easier just to separate them": Practice considerations in the mental health care and support of younger people with dementia and their families. Journal of Psychiatric and Mental Health Nursing 19(6): 555-562.

Roach, P., Keady, J., Bee, P. \& Hope, K. (2008). Subjective experiences of younger people with dementia and their families: Implications for UK research, policy and practice. Reviews in Clinical Gerontology 18(2): 165-172.

Royal College of Psychiatrists and Alzheimer's Society London. (2006). Services for Younger People with Alzheimer's Disease and Other Dementias. Council Report CR135. London: Royal College of Psychiatrists and Alzheimer's Society. 
Sabat, S. (2001). The Experience of Alzheimer's Disease: Life Through a Tangled Veil. Oxford: Blackwell.

Segal, L. (2013). Out of Time: The Perils and Pleasures of Ageing. London: Verso.

Steeman, E., Godderis, J., Grypdonck, M., De Bal, N. \& De Casterle, B. D. (2007). Living with dementia from the perspective of older people: Is it a positive story? Aging and Mental Health 11(2): 119-130.

Svanberg, E., Spector, A. \& Stott, J. (2011). The impact of young onset dementia on the family: A literature review. International Psychogeriatrics 23(3): 356-371.

Tindall, L. \& Manthorpe, J. (1997). Early-onset dementia: A case of illtiming? Journal of Mental Health 6(3): 237-249.

Tolhurst, E., Bhattacharyya, S. \& Kingston, P. (2014). Young onset dementia: The impact of emergent age-based factors upon personhood. Dementia 13(2): 193-206.

Weicht, B. (2011). Embracing dependency: Rethinking (in)dependence in the discourse of care. The Sociological Review 58(2): 205-224.

Weiss, R. \& Bass, S. (2002). Introduction. In R. Weiss \& S. Bass (eds.), Challenges of the Third Age: Meaning and Purpose in Later Life (pp. 3-12). New York: Oxford University Press.

Werner, P., Stein-Shvachman, I. \& Korczyn, A. (2009). Early onset dementia: Clinical and social aspects. International Psychogeriatrics 21(4): 631-636. 